\title{
Plagiarism: Deterrence, Detection and Prevention
}

Dr Jeremy B. Williams, Universitas 21 Global

1 Introduction 2

2 The 'New' Plagiarism 3

2.1 The scale of the problem 3

2.2 The different types of plagiarism 4

2.3 Detecting plagiarism 5

$\begin{array}{lll}2.4 & \text { The motivations for plagiarism } & 7\end{array}$

$\begin{array}{lll}2.5 & \text { Deterring and preventing plagiarism } & 8\end{array}$

3 Authentic assessment practice 11

3.1 Introduction 11

3.2 Managerial economics 11

4 Where next? 14

$\begin{array}{lll}4.1 & \text { Web resources } & 14\end{array}$

$\begin{array}{lll}4.2 & \text { Suggested reading } & 15\end{array}$

Appendix 1: Official assignment cover sheet containing generic assessment criteria and a declaration of originality of work 16

Appendix 2: Module website - assignment upload pop-up confirmation $\quad 17$

$\begin{array}{ll}\text { Notes } & 18\end{array}$

$\begin{array}{ll}\text { References } & 18\end{array}$ 
Charles Caleb Colton once observed that 'imitation is the sincerest form of flattery'. Whilst this may be apt in many instances, there is a point in the intellectual space where imitation is more akin to theft. This is certainly the case in the higher education sector where, in the internet age, the increasing incidence of student plagiarism has become a cause of concern.

Plagiarism may be defined as the use of another person's words and/or ideas without acknowledging that the ideas and/or words belong to someone else. It is not a new phenomenon, nor is it something exclusive to the discipline of economics, but there is little doubt that it is a growing problem that lecturers need to address systematically if the underlying causes, rather than the symptoms, are to be addressed. At the heart of the problem is the increasing availability of easily accessible electronic resources in recent times, whereupon it has become so much easier for students to 'cut and paste' slabs of unedited text. This can sometimes lead to assignments being submitted that are inadequately referenced, highly unfocused or, worse still, largely or entirely someone else's work.

This chapter considers the various strategies currently being employed to stamp out plagiarism. These include the use of 'honour codes' that incorporate punitive systems to discredit plagiarists, and the various proprietary and freeware packages available for the electronic detection of plagiarism. The discussion will concentrate, first of all, on the defining characteristics of plagiarism and how it manifests itself in the current university environment. This is followed by a brief discussion on the factors deemed to be responsible for plagiarism, and the mechanisms subsequently employed by various institutions to deal with its increasing incidence. The discussion concludes by arguing for an integrated approach founded upon a commitment to assessment regimes that reward critical analysis rather than content regurgitation. To proceed down this path, it is further argued that assessment items need to be designed in such a way as to present students with authentic learning environments: that is, settings for assessment that engage students with real and relevant tasks, with palpable and practical learning outcomes. Of all disciplines, economics is one that readily lends itself to this approach.

The main aim of the discussion, therefore, is to demonstrate that, while introducing measures to improve deterrence and detection of plagiarism is important, this is essentially a reactionary approach that is unlikely to yield lasting benefits. It is argued that the source of the problem is systemic, and that the focus needs to be on prevention of plagiarism through the use of innovative and engaging assessment. To this end, it is further posited that information and communications technologies (ICTs) can be of invaluable assistance - the very technologies that have led to the burgeoning student plagiarism problem in the first place. 


\section{The 'New' Plagiarism}

\subsection{The scale of the problem}

'Plagiarism' derives from the Latin word plagiarius, meaning 'kidnapper' or 'abductor'. It is the theft of someone's creativity, ideas or language; something that strikes at the very heart of academic life. It is a form of cheating and is generally regarded as being morally and ethically unacceptable.

- Always ensure that you
are familiar with your
institution's plagiarism
policies and regulations,
and be able to explain them
in jargon-free terms to the
students.
- Strike an appropriate
balance between
'encouragement' of the
learning process and the
potentially serious
consequences if plagiarism
is proven.
- A worthwhile exercise is to
spend some time in class
(or interactively online)
going through real examples
of what does and does not
constitute acceptable
practice. A suggested
method of doing this is
contained in section 3.

It should not be surprising, therefore, that plagiarism is such an emotionally charged issue. Discussing the matter with students in the first class meeting of term can be a little tricky.

'The New Plagiarism requires little effort and is geometrically more powerful. While the pre-modem student might misappropriate a dozen ideas from a handful of thinkers, the post-modem student can download and save hundreds of pages per hour. We have moved from the horse and buggy days of plagiarism to the Space Age without stopping for the horseless carriage.'

McKenzie (1998)

If evidence is required of this alarming rise in the incidence of plagiarism, it can be found in the extensive reproduction and distribution of student essays through online 'paper mill' companies - businesses that make up arguably one of the most successful internet industries after pornography and gambling. Indeed, as The Economist observed in the aftermath of the dotcom crash, these cheat sites are one of the few dotcom business models that continue to prosper (Anon., 2002).

Some sites rely on advertising revenue and supply services free-of-charge or facilitate exchange (students submitting a paper and getting one in return). In most cases, however, it is fee-for-service. Students can purchase pre-written or commissioned papers, and while the format varies slightly from one operator to another, customers can pay anywhere from US $\$ 1$ to $\$ 10$ per page.

While accurate statistics are not always easy to obtain, given the dynamism of the industry, cursory perusal of the websites of the leading companies would suggest that, taken together, these sites are likely to receive visitor numbers running into millions each week. For example, Schoolsucks.com, a long-time market participant with around 20,000 members, claims to have 250,000 hits per day. Meanwhile, another company claiming to have led the industry since 1995, Cheathouse.com, boasts a membership of over 140,000 (as of mid-2004), which continues to grow by a few hundred each day. The number of hits on a website does not correspond with the number of sales, of course, but equally, it is hard to imagine that everyone visits these sites out of curiosity.

The dramatic expansion of this online service is testimony to its commercial viability, as testified by the large number of advertisers these companies manage to attract to their sites. The full extent of the growth is well documented by the Kimbel Library at Coastal Carolina University, which maintains a comprehensive list of the world's cheat sites. In March 1999, there were around 35 such sites. By September 2003, this number had climbed to around 250 general sites, plus 80 subject-specific sites (Coastal Carolina University, 2002). 
Given these developments, it is not surprising that a large volume of literature has emerged in the last few years focusing on the subject of plagiarism in the higher education sector. The general consensus appears to be that, while plagiarism is not a new phenomenon, its incidence has grown in scale to the point where it is almost of epidemic proportions.

In the USA, for example, research indicates that cheating among undergraduate students has increased steadily over the past half-century or so from around 23 per cent to as much as 90 per cent (Drake, 1941; Jensen et al., 2002). It is true that some studies put the 'cheat rate' somewhat lower than this, but, these studies notwithstanding, there has been sufficient concern over the trend in student behaviour for the Center for Academic Integrity to be established, a consortium now comprising more than 320 institutions of higher education.

In the UK, meanwhile, the plagiarism problem has been considered serious enough for affected parties to seek the assistance of the Joint Information Systems Committee (JISC), a strategic advisory committee working on behalf of the funding bodies for further and higher education in England, Scotland, Wales and Northern Ireland, to investigate electronic solutions to the issue of plagiarism. The key outcome to emerge from this initiative was the establishment of a national plagiarism advisory service to act as a source of information for teaching staff and institutions, including a national electronic plagiarism detection service (see section 2.3).

\subsection{The different types of plagiarism}

Given the dramatic increase in its incidence, most universities around the world have made a point of including definitive statements on plagiarism in student handbooks and on university websites in the hope that no student standing accused of plagiarism can mount a defence on the grounds of their ignorance. The fact remains, however, that even proceeding on the basis that all students are diligent enough to read the 'fine print' in university policy documents, the scope of plagiarism is such that it incorporates a range of offences not easily defined in the space of a few sentences. In short, there will be instances where the extent of plagiarism is very serious, others when it will be relatively minor, and times when it falls somewhere in between. As a consequence, a range of policy responses is required to match the gravity of the offence. It is certainly important to send out a clear signal to the student body that plagiarism will not be tolerated, but it is also important to acknowledge the possibility of genuine cases of unintentional plagiarism, and to be wary, therefore, of over-zealous policing of plagiarism. In any case, it is essential that the institution be capable of distinguishing between intentional and unintentional plagiarism.

Without wanting to over-generalise, plagiarists may be identified as one of the following three types:

- the lazy plagiarist;

- the cunning plagiarist;

- the accidental plagiarist.

The 'lazy' plagiarist is generally an academically weak and otherwise under-motivated student, the type who would happily take the work of someone else in its entirety, do little more than to change the name on the paper and claim it for their own. This type of student may use the 'cheat sites' or simply steal the work of others - maybe that belonging to a student who studied the subject in a previous year. For this type of plagiarist, if a ready-made answer to a question cannot be found electronically, it simply cannot be worth having. The development of an educated opinion, a lively inquiring mind, a creative impulse: these things are not worthy of consideration. As this author once read in a student's e-mail signature: 'Clay's Conclusion: Creativity is great, but plagiarism is faster'. 
For those student plagiarists who elect not to procure work from their colleagues or consume the services of the online paper mills, there is still an abundance of other point-and-click plagiarism opportunities. Plain, old-fashioned laziness is certainly a factor, but internet-inspired indolence has given rise to a more refined form of sloth. The 'cunning' plagiarist is more sophisticated than the lazy plagiarist and takes full advantage of these abundant opportunities: they are quite clear about what plagiarism is, but work hard to avoid detection. Content is cutand-paste from a variety of sources on the Web (and possibly from other students' papers), with a view to manufacturing an answer. They may also attempt to cover their tracks through the provision of incomplete or inaccurate bibliographic details in their list of references, which make it more difficult to track their misdemeanours (Renard, 1999).

The 'accidental' plagiarist, by contrast, is not in the least bit devious. Their transgressions arise typically as a consequence of inexperience, poor study skills, local academic norms or some combination thereof. Such students typically insert slabs of unattributed text in their essays and, when challenged, will be either embarrassed by their sloppy referencing or genuinely surprised that they have been challenged at all, claiming ignorance of the system.

In many instances, it is international students who fall into this latter category, particularly those from East Asian countries. Apart from a lack of exposure to western academic norms when it comes to academic work, these students can sometimes experience difficulty in TOP
TIPS

- Always be sensitive to cultural differences that may confuse students' understanding of the plagiarism concept, especially those who are new to your country's education system.

- Encourage students to check with their tutor prior to submission as to whether they may have inadvertently broken (accepted) practice. constructing a critically analytical essay out of cultural respect for those in authority. This is sometimes mistaken for poor writing ability and/or a lack of ethics when the reality might be somewhat different. In Confucian cultures, for example, conventional wisdom is that the best ideas are those of the ancients, and their philosophy and insights are so wide-ranging that to challenge those ideas would be interpreted as quite an audacious act. Instead, memorisation and recitation are valued. It follows that to challenge 'the truths' handed down by 'the sages' who author textbooks and write lecture notes would be counter-cultural for students of this tradition (Smith, 1999).

Not everyone accepts this view, of course, and a standard response is that it should be a case of 'when in Rome do as the Romans do', with students observing the cultural norms of the country in which they are studying rather than those of their home country. Without going into an in-depth discussion of the validity of this argument, it is probably fair to say that firstyear students, in particular, might be extended some latitude, at least until they have had an opportunity to commence with the cultural transition and adjust to the different cultural norms.

In any event, some allowances will have to be made where assignments must be written in a second or third language. This is not to condone wholesale plagiarism; simply to recognise that writing in a foreign language engenders a strong temptation to get linguistic assistance.

\subsection{Detecting plagiarism}

Various strategies can be employed by academics to police plagiarism, ranging from simple Web search techniques used by individual lecturers, to the employment of easy-to-use freeware capable of tracking plagiarism between cohorts of students, as well as to quite elaborate systemic approaches involving the engagement of commercial plagiarism detection agencies.

While it is possible to detect plagiarism if assignments are submitted in hard copy, if these same assignments are submitted electronically, the whole process is made considerably easier because academics are in a position to 'fight fire with fire'. Armed with a good search engine, a lazy or accidental plagiarist can be exposed relatively easily. The first thing to do is to identify some 
suspicious-looking text: a paragraph with a discernible change in writing style, for example. Then, by copying a word string of, say, five to six words from this paragraph, enclosing in a set of inverted commas, and pasting into a search engine (for example, http://www.google.com, http://www.dogpile.com or http://www.mywebsearch.com), a list of potential source documents for the word string will be generated in the space of a few seconds. By clicking on one of the websites listed, it may be possible to locate the passage one is looking for with the naked eye. In the event that this is not possible, use the text copied from the student's essay, which is still stored on the computer clipboard, and paste it into the 'Find on This Page' option in the Edit menu of the Web browser: the precise location of the offending text on the website in question will be highlighted.

Suspicious-looking text need not be restricted to an inexplicable change in a student's writing style: the usual tell-tale sign in the case of the lazy or accidental plagiarist. It is possible to trip up the cunning plagiarist by running checks on the consistency of formatting in their essay. US English intermingled with UK English, font and text size changes, and carriage returns $(ل)$ or paragraph symbols (II) at the end of each line are usually quite reliable indicators of cut-and-paste activity. More subtle examples include the style of inverted commas, and the use of special characters like 'en dashes'. The inclusion of 'straight quotes' (" ") and consecutive hyphens (--) where you would normally expect to find 'curly quotes' (" ") and en dashes (-) may be also be a sign that there have been extensive cut-and-pastes from HTML documents.

Sometimes, extensive Web searches for evidence of plagiarism yield a nil return when all the indications suggests otherwise. In this instance, the process utilised for searching the Web needs to be repeated but, this time, to

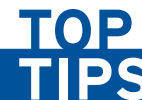

TIPS

- Familiarise yourself with the various plagiarism detection software packages and develop an efficient rubric for checking your submissions.

- Consider forming detection 'teams' with a view to providing an efficient division of labour and guidelines for best practice.

- Remain open-minded at all times. be done in conjunction with online databases (for example, ProQuest and EBSCO Host). Requiring a university library login, documents in these databases may not show up on the Web, and they are likely, therefore, to escape the clutches of a Google search. If this strategy fails to produce results, and the evidence suggesting plagiarism is compelling, then the text used may not be digitised (which obviously makes detection more difficult), or it could be that the student has been able to access the work of a colleague. In this instance, a program that compares the work of one student against that of another, both within and across cohorts, is of considerable assistance. One such program, available as freeware, has been devised by Lou Bloomfield at Virginia University (see section 4.1).

If academics find the policing of plagiarism too labour-intensive, there is always the option of out-sourcing the task to private enterprise. Indeed, almost as quickly as student cheat sites arrived on the scene, electronic student cheat detection services emerged to counter them. One company, Turnitin.com, has become very successful in this and is the leading supplier of plagiarism detection services in the world today, claiming to have a client base of more than 3,500 educational institutions in over 50 countries, including the UK where it services more than 700 institutions of further and higher education through JISC. For its source documents, Turnitin.com uses the current and an extensively archived copy of the publicly accessible internet, which includes more than 4 billion pages, updated daily at a rate of around 40 million pages per day. In addition, it uses millions of published works, including tens of thousands of electronic books, and journals accessible via ABI/Inform, Periodical Abstracts and Business Dateline. It also uses all the student papers that have ever been submitted to Turnitin.com.

Enlisting private companies as agents of the university to act in the capacity described above may clearly be a risky enterprise, and it is one that requires very careful consideration (especially as, in the early days, it was discovered by Lou Bloomfield that some plagiarism detection sites shared domain registrations and servers with several paper mills!). The British have been far more cautious than their North American counterparts in this respect: the detailed feasibility 
studies under the aegis of JISC provide evidence of this. In other parts of the world, such as Australasia, there has been even greater caution, perhaps reflecting the relative immaturity of the plagiarism detection industry and the general conservatism of educational institutions, although possibly also the cultural differences referred to earlier. This may change as plagiarism detection services become more established and develop a reputation, but then there is always the question of cost. In the UK, for example, the JISC has committed to fully funding its online plagiarism detection service until August 2005, at which time a sliding scale of charges will be introduced.

\subsection{The motivations for plagiarism}

To some, the increasing incidence of plagiarism in the higher education sector may be looked upon as perfectly acceptable behaviour. According to author and satirist Stewart Home, plagiarism 'saves time and effort, improves results, and shows considerable initiative on the part of the plagiarist' (cited in Duguid, 1996). This line of thinking is predicated upon the notion that there is nothing sinister about the liberal use of other people's ideas. To plagiarise is not to steal another's property, it is simply about the spread of information and knowledge.

Indeed, prior to the eighteenth-century European Enlightenment, plagiarism was useful in aiding the distribution of ideas and, in this sense, can be said to be an important part of western cultural heritage, up to that point in time. One might argue further that, with the new social conditions that have emerged with the widespread use of ICTs, it has once again become an inevitable part of contemporary culture, although for rather different reasons (Critical Art Ensemble, 1995). Allied to this is the increasingly results-driven education system, with its associated league tables, as well as the increasingly difficult labour market conditions for graduates, resulting from the UK's wider-access policy for higher education.

Taking a more sceptical view, if we accept that it is typically the academically weaker students who tend to engage in the various forms of plagiarism, it is unlikely that these individuals will, consciously or unconsciously, be part of any crusade to spread information and knowledge. On the other hand, as the statistics cited in section 2.1 would tend to indicate, it cannot be just they who are indulging in unethical practice (unless the majority of students can be described as academically weak!). Why is it, then, that students are resorting to plagiarism in increasingly large numbers?

Irrespective of a student's ability, pressure to plagiarise can emerge because of a variety of influences. These include, for example:

- poor time management skills (a problem often exacerbated because of the increasing competition for students' time arising from the need to work part time or care for children) and an inability to cope with workload (perhaps as a result of class timetables and the corresponding assessment tasks);

- a lack of motivation to excel because of a perception that the academic responsible for the class has little enthusiasm for the subject (the students then expending what they consider to be a commensurate amount of effort);

- increased external pressure to succeed from parents or peers, or for financial reasons;

- an innate desire to take on and test the system (particularly if the punishment associated with detection is relatively minor);

- cultural difference in learning and presentation styles where, in some settings, it is considered normal custom and practice to quote the experts without citation (Joint Information Systems Committee, 2003). 
This is by no means an exhaustive list of the factors that might be considered responsible for the frequency of plagiarism; suffice to say that it is an indicator of the complexity of the issue. Neither do these factors necessarily explain the increasing incidence of plagiarism. Indeed, many, if not all, of those reasons listed above were in existence prior to the dramatic increase in the number of reported cases of plagiarism. The key explanatory variable, it would seem, is the increasing availability of electronic text. It is this, coupled with any of the above motivations, that has spawned the seemingly inexorable rise in student plagiarism.

The spate of books on the subject, along with the various websites, media reports, conferences and symposia, is testimony to the amount of intellectual energy currently being dedicated to the topic of internet plagiarism. The major preoccupation is with both detection and deterrence: detection by resorting to 'fighting fire with fire' using various proprietary and freeware anti-plagiarism packages; deterrence through stressing the importance of education in ethics to ensure that students are not tempted to breach their university honour codes, and through the meting out of stiff penalties to offenders, to send a clear message that plagiarism is behaviour not to be tolerated in any circumstances.

\subsection{Deterring and preventing plagiarism}

The distinction between deterrence and prevention is, perhaps, not always clear. It is suggested that the former may be associated with the creation of a (perhaps, Utopian) environment where students never feel motivated to plagiarise; the latter creates an environment where, regardless of the

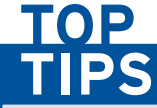

- Ensure that assessment construction minimises the ease with which plagiarism can be both difficult to resist by the student and difficult for staff to detect.

- Be flexible in allowing extensions to deadlines if you are convinced that the only alternative would be to receive a plagiarised submission.

- Overall, consider coordinating the timing of assignments in conjunction with other subjects, with a view to avoiding 'peak loading'. motivation, the chances of detection and punishment are uncomfortably high.

While many universities around the world would probably claim that their publicly stated policies and procedures will act as a deterrent to any student contemplating plagiarism, their publication alone is unlikely to cut any sway with would-be plagiarists. In North America, however, the punitive systems in place to discredit plagiarists tend to be an integral part of university-wide honour codes that, effectively implemented, can make students think long and hard about engaging in plagiarism. These university 'honour codes' have a long history, and they are treated very seriously by the authorities.

Recent events at the University of Virginia, one the oldest and most respected universities in the USA, have certainly cast a shadow of doubt over the efficacy of 'honour codes'. When Professor Lou Bloomfield tested his plagiarism detection software on 1,850 introductory physics papers at the University of Virginia in April 2001, the result sent shock-waves throughout the university community and beyond. The program found no fewer than 122 suspect papers and Bloomfield had no hesitation in handing over all the cases to the University of Virginia's Honor Committee (see Schemo, 2001). This might have been less of an issue were it not for the fact that, since 1842, the University of Virginia has benefited from the ethical standards set out in its Honor System, generally regarded as one of the university's most noteworthy and respected traditions. Lying, cheating and stealing are not tolerated and any student found guilty of such an offence is, without exception, dismissed permanently from the university.

Such a flagrant violation of an 'honour code' as celebrated as that of the University of Virginia surely begs the question as to the whether measures such as this have become an anachronism. Some commentators believe this is not the case, and argue instead that it is time for institutions to recommit themselves to a tradition of academic integrity and honour. Indeed, the available data do suggest that cheating at institutions with honour codes is significantly lower than at institutions without codes. The key, they argue, is that it must be a topic of on-going discussion, 
and by stressing the privileges afforded to students, a culture is created whereby unethical behaviour becomes socially unacceptable among students, and little sympathy will be extended to those who receive heavy penalties for attempting to beat the system (McCabe and Trevino, 2002).

\section{TOP TIPS}

- Create an explicit focus on learning outcomes students need to see the point of what they are doing.

- Design assessments that motivate students on the basis of the quality of their learning and the generic skills they acquire rather than the content they memorise.

- Design assessments where the learning experience is truly authentic, suitably contextualised, completed within a suitably limited time period and as specific to the university course unit as possible.

- Encourage students to roleplay and 'suspend disbelief' in assignments, so that they develop a much greater empathy for the subject matter (Chancellor of the Exchequer, CEO, etc.).

- Include the mandatory use of assignment cover sheets that incorporate signed declarations of originality.

- With an assignment that is to be submitted electronically, use pop-up confirmations about the conditions that a student is agreeing to when they upload their assignment (see the appendices to this chapter for examples of each).
The ability to analyse problems critically is not in abundance among those who elect to plagiarise material from the internet or from their peers, and as the discussion in the sections above demonstrates, the policing of this kind of activity can be a time-consuming business.

Formal tuition in the art of critical thinking is certainly a way forward, but this will not be time well spent if, subsequently, students are not presented with adequate opportunity to apply this important generic skill. All too often, assignments and examination questions are set that encourage the reproduction of content knowledge rather than critical appreciation of that content knowledge. Generally speaking, this tends to be a reflection of module design that is driven primarily by content considerations and where assessment is very much of an afterthought, rather than the other way around. In short, to be effective, assessment must be authentic: it must mean something to the student, so it will engage them and add value to their skill set.

As scholars such as Ramsden (1992) have argued, the quality of students' understanding is intimately related to the quality of their engagement with learning tasks. Setting tasks that test their memories or their ability to reproduce content material is not particularly engaging, and this is precisely what many assessment items require - the same assessment items that, coincidentally, lend themselves very well to cutting-and-pasting techniques.

A pertinent question to ask is whether students are entirely to blame for the plagiarism problem that plagues our universities. The study conducted by Ashworth et al. (1997) would suggest not. They conclude that cheating might be looked upon as a symptom of some general malaise. They found that students felt alienated from teaching staff because of their demeanour and their lack of contact with students. Assessment tasks that fail to engage students are a symbol of this gap between students and lecturers, and in the absence of any basic commitment on the part of the student that the work they are doing is significant, there is no moral imperative to refrain from plagiarism or cheating.

The point is that while one cannot 'turn a blind eye' to students' plagiarism, it would be fatuous to assume that it is the students who are at fault and the students alone. Could it be that students are cheating because they do not value the opportunity of learning in university classes? Is it conceivable that the pedagogy currently employed has not adjusted to contemporary circumstances? As one author has observed, 'we expect authentic writing from our students, yet we do not write authentic assignments for them' (Howard, 2002). It is worth considering why this might be so: one argument is that the everincreasing pressure on academics to teach, research and administer

- Exercise a firm commitment
to authentic assessments
that have the effect of
minimising the extent of
assignment recycling, even
to the point where every
assessment item is unique.
- Seek to encourage
departmental co-ordination
in a commitment to authentic
assessment as a strategy to
combat student plagiarism.
In this way, students can see
there is a synchronised
departmental effort to
change the way that learning
is assessed, and that there is
consistency of treatment
when it comes to meting out
penalties for plagiarism
offences.


reduces the time for creating imaginative and otherwise difficult-to-plagiarise (for example, individualised) assignments. As a consequence, there is much anecdotal evidence that academics are retreating back to the unseen, written examination as the sole method of assessing student performance in their courses.

As the literature on authentic assessment reveals, it is solidly based on constructivism, and acknowledges the learner as the chief architect of knowledge building (see, for example, Herrington and Herrington, 1998). It is a form of assessment that fosters understanding of learning processes in terms of real-life performance as opposed to a display of inert knowledge. The student is presented with real-world challenges that require them to apply their relevant skills and knowledge, rather than select from predetermined options, as is the case with multiple-choice tests, for example. Importantly, it is an approach that engages students because the task is something for which they will have an empathy, which, as the empirical evidence suggests, elicits deeper learning.

The key, therefore, is to set meaningful, situational questions relating to reallife, contemporary problems that engage students in the learning process. By making assignments as module-specific as possible (to prevent students from purchasing pre-written papers or paying outsiders to write answers), and by the examiners making it clear (as a stated objective of the module unit) that they are looking to reward evidence of depth of learning and sound critical analysis rather than recall of content knowledge, assignments are effectively cheat-proofed - although we must always be mindful of the increasing resource constraints placed upon academics.

Something of a paradigm shift is likely to be required if the changes described above are to be readily embraced by the majority of teachers in the higher education sector. However, it is worth mentioning that the various ICTs, used effectively, may well assist in this endeavour. Indeed, one could make the point that if as much energy and ingenuity went into developing new and exciting online devices for the purposes of facilitating assessment as there have been devoted to online devices for the detection of plagiarism, then maybe there would be fewer obstacles to negotiate.

In summary, while there is clearly a need to allocate some resources to detection and deterrence, these are essentially reactionary strategies. The proactive measure is the prevention of plagiarism through innovative pedagogy, as this is more likely to produce lasting results. Such an approach provides students with an incentive to learn. The natural corollary to this is that there will be less incentive for students to resort to plagiarism.

\section{TOP}

- Make it a requirement of assessment submissions that outlines and first drafts be submitted on specified dates in the lead-up to the final submission date. This means that the process of producing an assignment is evaluated as well as the final product (Carroll, 2002). This may not prevent some students copying from one another along the way, but it will thwart those individuals who look to produce the finished product while doing very little work themselves.

- Require students to submit a reflective journal describing their approach to the task, the methodology adopted, the problems encountered and how they resolved these problems.

- Hold random viva voce sessions that require students to defend and further explain, if necessary, what they have written. If this is clearly advertised to students in class and in course documentation, it will serve as an effective deterrent. 


\section{Authentic assessment practice}

\subsection{Introduction}

This section includes an example assessment item where the defining characteristic is its authenticity. The real-world problem at the heart of the question is brought to life through the integration of links to the World Wide Web and streaming media that serve to enhance engagement with the student.

Another key element is the inclusion of very specific instructions relating to the preparation and submission of the assessment items, which make it very difficult for a student to get someone else to do the work for them. Insisting that the work is submitted electronically in order to make use of plagiarism detection software is a deterrent. More importantly, however, there is little point in a student getting a friend or relative to write an answer for them if it is a condition that a student's answer makes direct references to module-specific materials. The student's accomplice would first have to become immersed in the subject materials - something that would be made doubly difficult if the time period allowed to complete the task were sufficiently tight.

In an economics module (of all modules), it is particularly important to devise assessment tasks that require application of empirical and theoretical knowledge to elements of professional practice. If assessment items are thoroughly grounded in authentic contexts, students have an excellent opportunity to apply their newly constructed knowledge in a meaningful way.

In summary, these examples attempt to engage students rather than alienate them. The opportunity for academically dishonest practice is less, but so is the temptation to resort to this kind of behaviour in the first place. Students will have a greater empathy for the task that lies before them if they can see the point of it and if it is explicitly related to their course of study.

\subsection{Managerial economics}

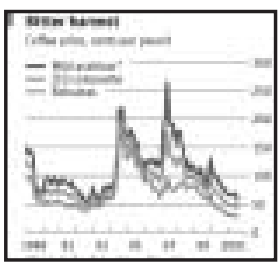

\section{The context}

The coffee industry has been experiencing significant difficulties in recent times, prices tumbling to all-time lows in real terms during 2002 (see Figure 1). This has caused considerable hardship for coffee producers around the world, but at long last there appears to be good news. After four years of record low prices, the International Coffee Organisation (ICO) composite price index shows average prices to be trending upwards. From an average price of 48 cents a pound in 2002 , to 52 cents a pound in 2003, the first quarter of 2004 saw an average price of around 59 cents a pound.

However, as a recently published World Bank discussion paper reveals, market dynamics within the coffee industry are complex and require careful analysis. An interesting development is the emergence of a segmented product market, differentiated according to a variety of characteristics including, for example, distinctive origin, organic production and fair trade. 
The fair trade lobby has certainly received a lot of attention of late as cappuccino consumers in the malls and high streets in developed countries have begun to voice their concern about the plight of coffee farmers in the less developed world. Ten years ago, the world coffee market was worth \$US30 billion and farmers received about \$US10 billion. Now the industry is worth \$US60 billion and the farmers get about \$US5.5 billion.

Berkeley, California, for example, has even considered banning the sale of

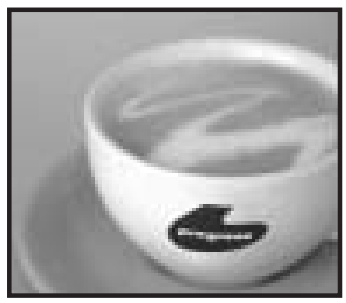
coffee that is not 'fair trade'. Oxfam, meanwhile, has taken a decisive step and joined forces with the UK's largest independent coffee roaster, Matthew Algie, announcing plans to launch a chain of fair trade coffee shops, called Progreso, in partnership with coffee grower cooperatives.

While support for the fair trade lobby has certainly grown in recent years, it faces opposition from free market economists like those at the Adam Smith Institute, who claim that fair trade fosters inefficiency and that, ultimately, this will not help farmers in less developed countries (LDCs).

\section{Your task}

The chief executive officer (CEO) of your company, a large multinational coffee roaster and retailer, has been advised by the board of directors that shareholders are becoming increasingly concerned about the poor public image of the company as a result of consumer complaints about exploitation of coffee farmers in LDCs. The CEO is unsure how to respond to this problem. She has read the Executive Summary of the World Bank discussion paper but remains confused. To this end, she is seeking the counsel of staff within the organisation and has called for submissions in the form of discussion papers.

Your brief is to explain the structure of the coffee industry and comment on recent trends using the relevant economic theory.

About 80 per cent of your discussion paper should be devoted to this task. The remaining 20 per cent should focus on possible strategies that the firm might take to alleviate the concerns of the shareholders.

The CEO is aware that a brief as broad as this is likely to attract a variety of proposals, but this is quite deliberate on her part as she wants to encourage people to come up with some creative solutions to the problem.

\section{Guide to the assessment task}

To help guide your thinking, you have discussed the matter with colleagues and, among other things, they recommend you contemplate the following:

- When explaining the structure of the coffee industry, be sure to discuss both the long-term perspective and the recent changes that have taken place.

- Use economic concepts to analyse the industry under four separate headings:

(1) the trends facing the farmers who grow the coffee beans;

(2) the changes occurring in the coffee roasting and retailing industry;

(3) the trends in the consumer markets for coffee;

(4) the responses from governments (or those that might be forthcoming). 
- Illustrate your explanations with diagrams, and before suggesting a strategy, or strategies, for the company, start by explaining to the shareholders the factors which might have caused the drop in farmer receipts from US $\$ 10$ bn to US $\$ 5.5$ bn over the last 10 years.

\section{Important information regarding the preparation of your work}

(1) In completing this task, be sure to draw on the concepts and analytical tools you have learnt about during the module, making direct reference to subject materials (i.e. the prescribed text, courseware and other resources). Students who fail to comply with this directive will find it difficult to receive a pass mark.

(2) You must upload a written response of 2,000 words (+/- 10\%, excluding references) in 24 hours' time via the link at the module website. Take a look at this link now, so that you know what is required.

(3) The piece of writing you submit should be referenced in the normal way, using an internationally recognised referencing system (e.g. the Harvard system and the numbered notes system). Students who fail to comply with this directive will not receive a pass mark.

(4) This is a broad question that invites a variety of 'equally correct' answers.

(5) High marks will be awarded for good, critical analysis, rather than for content merely cut and pasted from websites and other electronic sources.

(6) At all times, ensure that you acknowledge all sources and text that consist of more than $\mathrm{x}$ words [as per institution's regulations] that are not your own. 


\title{
4 Where next?
}

\subsection{Web resources}

\author{
http://online.northumbria.ac.uk/faculties/art/information_studies/Imri/Jiscpas/site/ji \\ scpas.asp \\ The JISC-funded Plagiarism Advisory Service is based in the Information management Research \\ Institute at Northumbria University. Among other things, the service provides general advice to \\ institutions, academics and students, a portal to online resources on the issue of plagiarism, and \\ an electronic detection service.
}

\section{http://www.coastal.edu/library/pubs/mills2.html}

The Coastal Carolina University Kimbel Library provides an authoritative list of the world's cheat sites.

\section{http://www.academicintegrity.org}

The Center for Academic Integrity (CAI) is affiliated to the Kenan Institute for Ethics at Duke University. It is a consortium of over 320 institutions in North America which aims to provide a forum to identify and affirm the values of academic integrity. It has a useful link to the honour codes of its member universities.

\section{http://www.plagiarism.phys.virginia.edu}

This plagiarism resource site has been created by Lou Bloomfield, University of Virginia. It includes a link to WCopyfind, a free plagiarism detection program. It cannot search the Web to find matching documents, but it can make comparisons between locally stored files. It is very simple to use and effective in checking for similarities between student assignments across semesters.

\section{http://clb.ed.qut.edu.au/events/projects/ndp/}

This Queensland University of Technology site documents approaches to non-deliberate plagiarism, where it is evident that there is no intention to cheat or steal ideas, but where, for cultural and/or linguistic reasons, students fall foul of university regulations.

\section{http://www.umuc.edu/distance/odell/cip/links_plagiarism.html}

The Center for Intellectual Property at the University of Maryland University College (UMUC) maintains one of the most comprehensive websites in the world on plagiarism-related issues.

\section{http://faculty.goucher.edu/writingprogram/sgarrett/plage1.asp}

This is a link to a 'plagiarism-risk quiz' (using passages from an economics text) developed by the Goucher College Writing Program. It is an interactive resource that students might find helpful. 


\subsection{Suggested reading}

Bannister, P. and Ashworth, P. (1998) 'Four good reasons for cheating and plagiarism', in C. Rust (ed.), Improving Student Learning Symposium, Centre for Staff Development, Oxford Brookes University, Oxford.

Carroll, J. (2002) A Handbook for Deterring Plagiarism in Higher Education, OCSLD, Oxford Brookes University, Oxford.

Groarke, M. Oblinger, D. and Choa, M. (2001) 'Term paper mills, anti-plagiarism tools, and academic integrity', Educause Review, vol. 36, no. 5, pp. 40-8.

Harris, R. A. (2001) The Plagiarism Handbook: Strategies for Preventing, Detecting and Dealing with Plagiarism, Pyrczak Publishing, Los Angeles, CA.

Herrington, J. and Herrington, A. (1998) 'Authentic assessment and multimedia: how university students respond to a model of authentic assessment', Higher Education Research and Development, vol. 17, no. 3, pp. 305-22.

Lathrop, A. and Foss, K. (2000) Student Cheating and Plagiarism in the Internet Era: A Wakeup Call, Libraries Unlimited, Englewood, NJ.

Park, C. (2003) 'In other (people's) words: plagiarism by university students - literature and lessons', Assessment \& Evaluation in Higher Education, vol. 28, no. 5, pp. 471-88.

Wiggins, G. (1990) 'The case for authentic assessment', Practical Assessment, Research \& Evaluation, vol. 2, no. 2, online at http://PAREonline.net/getvn.asp? $\mathrm{v}=2 \& \mathrm{n}=2$ (last accessed 12 June 2004). 


\section{Appendix 1: Official assignment cover sheet containing generic assessment criteria and a declaration of originality of work}

\section{University logo \\ OFFICIAL ASSIGNMENT COVER SHEET}

Student Name: Student Number:

Assignment Number: Title:

Instructor's Name:

Due Date: Subject Code and Name:

\section{DECLARATION OF ORIGINALITY OF WORK:}

I/we affirm that the attached work is entirely my/our own except where the words or ideas of other writers are specifically acknowledged through the use of inverted commas and in-text references. This assignment has not been submitted for any other subject at Univ X (or other institution). I/we have revised, edited, and proofread this paper.

Student signature:

Word count:

(Double-click on this check box in the absence of an electronic signature)

\begin{tabular}{|c|c|c|}
\hline Assessment Criteria & $\begin{array}{l}\text { Grade } \\
\text { S/U* }\end{array}$ & Comments \\
\hline $\begin{array}{l}\text { Demonstrated the ability to communicate } \\
\text { according to the normal conventions with } \\
\text { respect to language use, grammar and } \\
\text { referencing. }\end{array}$ & & \\
\hline $\begin{array}{l}2 \text { Demonstrated the ability to identify, select } \\
\text { and use essential readings. }\end{array}$ & & \\
\hline $\begin{array}{l}3 \text { Included relevant supportive qualitative } \\
\text { and/or quantitative data, which were } \\
\text { presented in a clear and integrated way. }\end{array}$ & & \\
\hline $\begin{array}{l}4 \text { Analysed, critically, the issues using } \\
\text { appropriate concepts and methods. }\end{array}$ & & \\
\hline $\begin{array}{l}5 \text { The key elements of the topic were outlined } \\
\text { and clearly justified. }\end{array}$ & & \\
\hline $\begin{array}{l}6 \text { Conclusions were developed clearly, logically } \\
\text { and concisely. }\end{array}$ & & \\
\hline \multicolumn{2}{|c|}{$\begin{array}{l}* S=\text { satisfactory; } U=\text { unsatisfactory. To achieve a passing } \\
\text { grade, criterion number } 1 \text { must be assessed as satisfactory. }\end{array}$} & Percentage: \\
\hline \multicolumn{2}{|l|}{ Signature of examiner: } & Date: \\
\hline
\end{tabular}


Appendix 2: Module website - assignment upload pop-up confirmation

\section{Consent statement}

By clicking on the check box below, I am acknowledging that I understand what plagiarism means; namely, that it is the presentation of an assignment by a student that has been copied in whole, or in part, from another student's work or from another source (e.g. published book, journal or web site) without due acknowledgement in the text.

To this end, I/we affirm that the work is entirely my/our own except where the words or ideas of other writers are specifically acknowledged through the use of inverted commas and in-text references. This assignment has not been submitted for any other subject at University X or any other institution. I have revised, edited, and proofread this paper.

I also freely accept my work may be used as a source document for the purpose of detecting plagiarism.

(Click on this check box if you consent to the above.) 


\section{Notes}

1 See, for example, those listed at the Center for Academic Integrity website: http://www.academicintegrity.org/samp_honor_codes.asp (last accessed 12 June 2004).

2 See the Honor Committee website at the University of Virginia: http://www.virginia.edu/honor (last accessed 12 June 2004).

\section{References}

Anon. (2002) 'Plagiarise: let no one else's work evade your eyes', The Economist, online at http://economist.com/PrinterFriendly.cfm?Story_ID=1033832 (last accessed 12 June 2004).

Ashworth, P., Bannister, P. and Thorne, P. (1997) 'Guilty in whose eyes? University students' perception of cheating and plagiarism in academic work and assessment', Studies in Higher Education, vol. 22, no. 2, pp. 187-203.

Carroll, J. (2002) A Handbook for Deterring Plagiarism in Higher Education, OCSLD, Oxford Brookes University, Oxford.

Coastal Carolina University (2002) 'Kimbel Library - cheating 101: internet paper mills', online at http://www.coastal.edu/library/pubs/mills2.html (last accessed 12 June 2004).

Critical Art Ensemble (1995) Utopian Plagiarism, Hypertextuality, and Electronic Cultural Production, online at http://college.hmco.com/english/amore/demo/ch5_r4.html (last accessed 12 June 2004).

Drake, C. A. (1941) 'Why students cheat', Journal of Higher Education, vol. 12, pp. 418-20.

Duguid, B. (1996) 'The unacceptable face of plagiarism?', online at http://media.hyperreal.org/zines/est/articles/plagiari.html (last accessed 12 June 2004).

Herrington, J. and Herrington, A. (1998) 'Authentic assessment and multimedia: how university students respond to a model of authentic assessment', Higher Education Research and Development, vol. 17, no. 3, pp. 305-22.

Howard, R. M. (2002) 'Don’t police plagiarism: just teach!', Education Digest, vol. 67, no. 5, pp. 46-9.

Jensen, L. A., Arnett, J. J., Feldman, S. S. and Cauffman, E. (2002) 'It's wrong, but everybody does it: Academic dishonesty among high school and college students', Contemporary Educational Psychology, vol. 27, no. 2, pp. 209-28. 
Joint Information Systems Committee (JISC) (2003) 'Why do students plagiarise?', online at http://www.jisc.ac.uk/index.cfm?name=plagiarism_why (last accessed 12 June 2004).

McCabe, D. and Trevino, L. K. (2002) 'Honesty and honor codes', Academe, vol. 88, no. 1, online at http://www.aaup.org/publications/Academe/2002/02JF/02jfmcc.htm (last accessed 12 June 2004).

McKenzie, J. (1998) 'The new plagiarism: seven antidotes to prevent highway robbery in an electronic age', From Now On: The Educational Technology Journal, vol. 7, no. 8, online at http://www.fno.org/may98/cov98may.html (last accessed 12 June 2004).

Ramsden, P. (1992) Learning to Teach in Higher Education, Routledge, London.

Renard, L. (1999) 'Cut and paste 101: plagiarism and the net', Educational Leadership, vol. 57, no. 4 , pp. 38-42.

Schemo, D. J. (2001) 'U. of Virginia hit by scandal over cheating', The New York Times, 10 May, online at http://www.nytimes.com/2001/05/10/national/10CHEA.html (last accessed 24 May 2004).

Smith, D. (1999) 'Supervising NESB students from Confucian educational cultures', in Y. Ryan and O. Zuber-Skerritt (eds), Supervising Postgraduates from Non-English-speaking Backgrounds, SRHE and Open University Press, Buckingham. 
The Handbook for Economics Lecturers 